\title{
Urinalysis - A Diagnostic Factor for Urolithiasis and Prognostic Factor for its Recurrence in Young Ruminants
}

\section{Mohsin Ali Gazi ${ }^{1 *}$, Makhdoomi DM ${ }^{1}$, Mir SA² and Sheikh GN $^{3}$}

${ }^{1}$ Division of Surgery and Radiology, Sheri Kashmir University of Agricultural Sciences and Technology Kashmir, Jammu and Kashmir, India

${ }^{2}$ Division of Pharmacology and Toxicology, Sheri Kashmir University of Agricultural Sciences and Technology Kashmir, Jammu and Kashmir, India

${ }^{3}$ Division of Epidemiology and Preventive Medicine, Sheri Kashmir University of Agricultural Sciences and Technology Kashmir, Jammu and Kashmir, India

\begin{abstract}
The experiment was a completely randomized block design with 6 groups awarded different treatments including 17 rams, 12 bucks and 113 calves. Animals clinically manifesting urolithiasis from field were merely screened as stone and non-stone formers. All replicates were run under different clinical situations with the objectives to screen calves as stone formers and non-stone formers and to ascertain recurrence risk due to residual fragments in future, and estimate urine biochemical analysis to ascertain a diagnostic factor for urolithiasis and prognostic factor for its recurrence that would help to evolve prophylactic protocol. Crystal formation indicated that urine was sufficiently saturated which support the formation and growth of uroliths. The, male calves showing numbers of crystals with a concomitant inflammatory process are at risk for calculi formation. Alterations in Urinary Calcium Phosphorous and Magnesium cannot be fixed as a diagnostic or prognostic value for detection of uroliths forming animals to a fear degree of accuracy. Urinalysis is simple and reliable test to confirm urinary tract disease and identify pathophysiology mechanisms associated with the underlying cause.
\end{abstract}

Keywords: Urolithiasis; Ruminants; Bovines; Calves

\section{Introduction}

Urinalysis is a screening and/or diagnostic tool as it can help detect substances or cellular material in the urine associated with different metabolic and kidney disorders. It is widely and routinely to detect any abnormalities that require follow up. The Clinical manifestation of urolithiasis in Ovine and caprine are remarkably different than in bovines. They may show Partial obstruction and complete obstruction with ruptured urinary bladder and hence demand different surgical protocols ranging from amputation of urethral process, Cystorehexsis and tube cystotomy/Bladder marsupialisation depending upon the diverse clinical situations. In sheep and goats abdominal ultrasound, may be useful for the diagnosis and prognosis of this disease $[1,2]$ to detect stones of different shapes and sizes [3].

Between Year 2011 and 2013, over 106 calves were treated who were suffering from urolithiasis; there was a dramatic increase in the prevalence during these years from overall $9.6 \%$ to $14.02 \%$ in 2013 . Since 2008, the frequency of urolithiasis in calves has increased more than 8 -fold. This reversion in urolith prevalence is continuing. Despite the difficulty of obtaining samples from dysuric patients and the urgency to provide therapy, it importantly requires collection prior to therapy to arrive at accurate interpretation of results. The method of collection, the duration and method of storage are essential to fully interpret results. The present clinical study was undertaken to predict the animals manifesting clinical urolithiasis in future and to ascertain the possibility of urolithiasis recurrence by examining crystal load in urine of the animals post treatment.

\section{Materials and Methods}

The study was conducted on clinical cases presented for surgical treatment of urolithiasis at Veterinary Clinical Complex Shuhama Kashmir, for a period of one year. Calves aged between 3 to 18 months and sheep and goat manifesting urolithiasis formed the subject for the study. An attempt has been made to find out the probable cause of the Urolithasis and to ascertain the recurrence of the disease.

\section{Anamnesis}

Anamnesis included previous history eliciting information about the previous treatment, nutritional history, related to type of feed, change of feed present ailment and symptoms. The clinical examination was done, where the status of the eyeballs, visible mucous membranes, smell of breath, was recorded. Much emphasis was laid for urinary conduct examination regarding, presence of calculi in the palpable part of urethra right from external urinary orifice pre scrotal, post scrotal and ischial part of urethra, pattern of urination, bladder distension, ruptured and intact bladder, degree of abdominal distension and abdominal thrill on the basis of which grouping of animals was done. This experiment was a completely randomized block design with 113 calves, 17 rams and 12 bucks. All the rams and bucks and 33 calves were clinically manifesting urolithiasis. 80 calves from field were merely screened as stone and non-stone formers. There were 6 groups awarded different treatments. All replicates were run in as presented, under different clinical situations with the objectives to screen calves as stone formers and non-stone formers and to ascertain recurrence risk due to residual fragments in future, and estimate urine biochemical analysis to ascertain a diagnostic factor for urolithiasis and prognostic factor for its recurrence that would help to evolve prophylactic protocol.

\section{Grouping of animal}

The animals were divided into six groups as under: 33 calves were divided into three groups as, Group A $(n=12)$. The calves showing

*Corresponding author: Mohsin Ali Gazi, Division of Surgery and Radiology, Sheri Kashmir University of Agricultural Sciences and Technology Kashmir, Jammu and Kashmir, India, Tel: 0191-226-2134-135; E-mail: mohsingazi9975@gmail.com

Received December 17, 2015; Accepted May 16, 2016; Published May 20, 2016

Citation: Gazi MA, Makhdoomi DM, Mir SA, Sheikh GN (2016) Urinalysis - A Diagnostic Factor for Urolithiasis and Prognostic Factor for its Recurrence in Young Ruminants. J Veterinar Sci Technol 7: 336. doi:10.4172/2157-7579.1000336

Copyright: @ 2016 Gazi MA, et al. This is an open-access article distributed under the terms of the Creative Commons Attribution License, which permits unrestricted use, distribution, and reproduction in any medium, provided the original author and source are credited. 
crouching Posture, Slight tenderness of abdomen, urinary thrill and hairs on body stood erect. Group B (n 12) includes the calves with uraemic breath, mild conjuctival congestion, recumbency, fluid thrill in abdomen. Group C (n 9), the calves were flexic with severe conjunctival congestion and massive bilateral distension. Sheep with ruptured urinary Bladder were put in Group $\mathbf{D}(n=9)$ and those with intact Urinary Bladder were grouped as Group $\mathbf{E}(n=8)$. The caprine cases were grouped as Group F ( $n=6$ ) as low risk Group and Group G $(\mathrm{n}=6)$ high risk Group

\section{Urine sample collection}

In apparently healthy animals the samples were collected in the wide mouth plastic vials as soon the animals voided urine or preputial massage was done to collect the sample. In other cases Cystocentesis was performed a site, 5 inch lateral and parallel to the penile urethra using a 6 inch long spinal needle. After collection of sample the needle was withdraw and the site was mopped and urine was processed for urinalysis. In general from day 0 , day 7 , after surgery, urine was collected from the catheter (Figure 1). After the urinary catheter was removed normal spontaneous urine was collected through the preputial opening.

In 30 cases, urine samples were collected during laprocystotomy. Those samples collected in clinical complex were immediately processed for screening while those urine samples collected from the field were preserved using 1 drop of $40 \%$ formaldehyde to $30 \mathrm{ml}$ urine and were processed for screening within 24 hours using urine analyzer (Urine analyzer - Uri-plus 200 Crest Biosystems, Division of coral clinical systems, Alto Santa Cruz complex P.O, Goa-403 202, India).

\section{Screening of animals as stone formers and non-formers}

In present study we used digital urine analyzer for speedy evaluations and that would bypass laborious laboratory procedures. 50 urine samples from 30 calves, 13 bucks and 7 rams were subjected to screening by urine analyzer. In case, where analyzer was not available the screening was done as per method of Teotia [4]. The urine sample was being collected in urine collecting bag. Each sample was filtered through Whatman filter paper No 1 to remove any crystalline material and mucous etc. $50 \mathrm{ml}$ of the urine were taken in a $100 \mathrm{ml}$ beaker. The $\mathrm{pH}$ was adjusted to 6.00 and four drops of chloroform were added to prevent growth of bacteria. Glass fibers of $0.05 \mathrm{~mm}$ diameter were suspended with a thread in the center of the urine sample. Calcium chloride $(0.1 \mathrm{ml})$ and sodium oxalate solution $(0.1 \mathrm{ml})$ was diffused in the urine by means of filter paper wicks. The glass fibers got coated

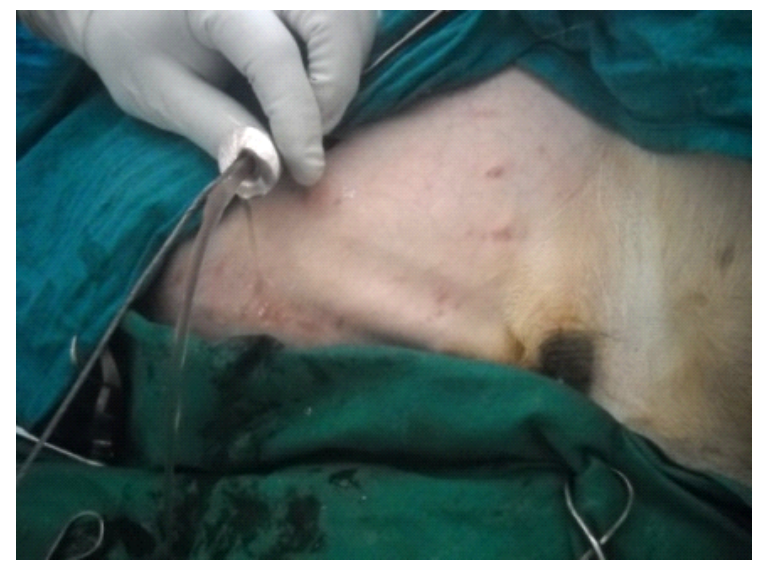

Figure 1: Collection of urine sample in a calf with silver nitrate for 30 minutes. The fibers were counter stained with Safranin solution for a period of 2 to 3 minutes. The presences of the crystals on the fiber under microscope were screened as positive for stone formation. The animals were screened for crystal urea/ urolithiasis up to 8 weeks using urine analyzer.

\section{Crystal estimation of urine}

After the institution of surgical treatment (different for different animals), the screening of urine for presence of crystal load was done at, 24 and 72 post-operative hour, and on the date of normal restoration of urine flow / at the time of removal of catheter post-operatively. This was followed at 2, 4, 6 and 8 weeks.

\section{Biochemical analysis of urine}

The urine samples were filtered using Whatman filter paper no 1 to remove any crystalline material and mucous etc. The samples were centrifuged and the supernatant taken for the estimation of Calcium [5], Phosphorus and Magnesium [6], using diagnostic kits (Miles India limited, Baroda Gujarat state, India).

\section{Results}

A record of anamnesis of the present study revealed two things in common. All the animals whether calves, sheep or bucks were in preruminant stage and were fed rations pre maturely. The ration offered included rice bran, rice straw or commercial feeds either alone or in combination. $60 \%$ bovine calves and $40 \%$ caprine and ovine kids had received previous treatment which included diuretic injections. The rest others had been given steroids, analgesics or tranquilizers.

\section{Stone former and non-stone former}

A total of 113 calves were subjected to screening as stone former and non-stone former. The fresh samples $(n=33)$ were screened for presence and absence of crystals. 100 percent cases were positive for presence of different forms of crystals. The degree of positivity ranged $48.48 \%$ as highly ( 16 out of 33$)+++, 30.30 \%$ moderately positive (10 out of 33$)++$ and $21 \%$ mildly positive $(7$ out of 33$)+$, differentiated as having crystals. Out of 80 samples collected from field, subjected to screening as stone and non-stone formers by method as described by Teotia [4], 41.25\% (34) were confirmed as positive and $58.75 \%$ cases were confirmed as negative. Among positive cases, 20 cases $(58.82 \%)$ were highly positive " +++ ". 8 cases $(23.52 \%)$ were moderately positive "++" and 6 cases (17.64\%) were mildly positive "+".

Out of 67 stone former positive cases 21 (31.34\%) were presented to our University hospital with clinical manifestations of urolithiasis for treatment within span of 8-12 weeks (Table 1). In some cases the urine showed heavy crystal load even after operation for some time.

An average of measurements taken in quadruplicate over 2 collections both pre and post-operative collections periods (Table 2) revealed that the crystal score was positive in all the groups under study, however the score was statistically non-significant in all other groups except group A, where it was 23.10 and decreased post operatively to 12.80 with a mean of 2.75 . The score however decreased significantly after surgery but the animals continued to show the crystal score positive due to the residual effect of the preexisting cause. As for the number of the crystals counted group A recorded highest (278.6) followed by groups D (237.4), C (229.00) and G (212.7).

\section{Patterns of crystals in urine}

The results of the present study reveal that the types of the crystals 
varied in different species of animals. In calves crystals were triple Phosphate, Calcium/Amorphous Phosphate, calcium Carbonate, Calcium oxalate, Uric acid and mostly the calculi were Silica ++ to ++++ . The shape of crystals was Prismatic, coffin lid shaped, star and elongated rod shaped, feathery or fern like (Table 2).

In sheep the type of crystals are calcium oxalate, triple Phosphate and Uric acid which shaped Spherical granules, amorphous rosette shaped, a cluster of 1 to 4 while in bucks hexagonal struvite type of crystal were seen (Table 3 ). The detailed microscopic examination of sediment revealed organized sediments +++ , erythrocytes four cases of calves, 2 sheep and two bucks each, leucocytes (2-4/hpf) in calves and occasional in sheep and Bucks, epithelial cells casts (10-12/hpf), in calves and 6-8/hpf in Sheep and bucks each, glucose was negative in all the cases of all the species of animals, and casts and in general RBC $(0-4 / \mathrm{hpf})$ were observed during microscopic examination of urine.

\section{Urinary calcium phosphorous and magnesium}

The results of urinary calcium, phosphorous and magnesium ( $\mathrm{mmol} /$ liter) in urine before and after surgery at various intervals of obstructive urolithiasis in different Groups are presented in Table 4. There was significant $(\mathrm{p}<0.05)$ increase in the urinary calcium levels from the day of admission of the animals for treatment to the phase of recovery. The urinary calcium levels at day zero were lower than normal in all the groups from A1 to G group viz., 4.91, 4.81, 5.43, 7.02, 4.58, 4.91, 4.85 and $4.84 \mathrm{~m}$ moles/litre. By 24th post treatment hour, there was recovery toward normal in the levels and by 72 post-surgical hour till restoration of normal urine flow irrespective of the severity of disease, the urinary calcium was within the physiological range. The severity of the disease affected significantly $(\mathrm{P}>0.05)$. There was significant $(\mathrm{p}<0.05)$ increase in the urinary calcium levels from the day of admission of the animals for treatment to the phase of recovery. At day zero, there was increase in urinary phosphorous levels with the severity of disease in all the groups under study. However, 24 and 72 post-surgical hour and at the time

\begin{tabular}{|c|c|c|c|}
\hline \multirow{3}{*}{ Total Cases 113} & Stone Formers & 67 & $59.29 \%$ \\
\hline & Non-Stone Formers & 46 & $40.70 \%$ \\
\hline & Cases presented from Stone Formers & 21 & $31.34 \%$ \\
\hline \multirow{4}{*}{$\begin{array}{c}\text { Fresh Cases } \\
\quad 33\end{array}$} & Cases +ve & 33 & $100 \%$ \\
\hline & Mild & 07 & $21.22 \%$ \\
\hline & Moderate & 10 & $30.30 \%$ \\
\hline & High & 16 & $48.48 \%$ \\
\hline \multirow{5}{*}{ Field Cases 80} & Cases +ve & 34 & $48.48 \%$ \\
\hline & Mild & 06 & $17.64 \%$ \\
\hline & Moderate & 08 & $23.52 \%$ \\
\hline & Severe & 20 & $58.82 \%$ \\
\hline & $\begin{array}{l}\% \text { Cases presented for Urolithiasis } \\
\text { among non-stone formers }\end{array}$ & $21 / 34$ & $61.75 \%$ \\
\hline
\end{tabular}

Table 1: Screening of animals from University Hospital and Field as stone and non-stone formers. of removal of catheter, the variability levels in urinary phosphorous among different groups was varying significantly $(\mathrm{P}>0.05)$. With the advancement of post-treatment period, there was significant $(p<0.05)$ decreasing trend in the urinary phosphorous levels within normal range on restoration of free urine flow irrespective of the severity of the disease. The postoperative observations of urinary phosphorous were almost reverse to the calcium levels and postoperative lowering of urinary phosphorous was observed in the animals of all groups at all the postoperative intervals. On the day of hospitalization, the urinary magnesium levels were high depending upon duration of disease in all the groups under study. However, at 24th and 72 post-surgical hour till the time of removal of catheter, the variability levels in urinary magnesium among different groups was varying significantly $(\mathrm{P}>0.05)$. With the advancement of post-treatment period, there was significant $(\mathrm{p}<0.05)$ decrease in the urinary magnesium levels within normal restoration of urinary flow.

\section{Residual effect of urolithiasis}

The incidence of recurrence clinically at 2 nd week post operatively included two animals from calves, one am. In 4th post operative week, the recurrence cases included two calves one ram and two bucks. In 6th week one calf was reported with the recurrence (Table 5).

\section{Discussion}

The diagnosis of urolithiasis is based on a complete anamnesis and physical examination, and may be complemented by laboratory tests (of blood and urine), ultrasonography and radiography of the urinary tract [1,7]. In present study $75 \%$ calves had received diuretics and all such animals had ruptured urinary bladder which has not been evaluated in urolithiasis with calcium oxalate uroliths calves so for. Cystocentesis consists in the transabdominal collection of urine from the urinary bladder (Figure 3), under ultrasonographic control (Figure 4). It may increase the patient's comfort and temporarily alleviate bladder distension in turn reducing the risk of necrosis and rupture, but bladder leakage and subsequent uroperitoneum must be

\begin{tabular}{|c|c|c|c|c|c|c|c|}
\hline \multicolumn{7}{|c|}{ Crystal Score (1-5) } \\
\hline Collection & A & B & C & D & E & F & G \\
\hline Pre Collection & 23.10 & 2.40 & 2.33 & 2.75 & 2.15 & 2.37 & 2.54 \\
\hline Post Collection & 12.80 & 2.20 & 1.76 & 2.50 & 1.63 & 2.16 & 1.98 \\
\hline Mean & 2.75 & 2.80 & 2.04 & 2.63 & 1.89 & 2.35 & 2.18 \\
\hline
\end{tabular}

\section{Number of Crystals Counted}

\begin{tabular}{|c|c|c|c|c|c|c|c|}
\hline Pre Collection & 278.6 & 196.2 & 229.3 & 237.4 & 156.8 & 181.4 & 212.7 \\
\hline Post Collection & 132.5 & 103.5 & 43.8 & 118.0 & 28.6 & 72.9 & 73.6 \\
\hline Mean & 205.6 & 49.8 & 136.5 & 177.7 & 92.7 & 127.2 & 143.2 \\
\hline
\end{tabular}

Table 2: Showing Crystal Score (1-5) and number of crystals.

\begin{tabular}{|c|c|c|}
\hline Species & Type of crystals & Shape of crystals \\
\hline \multirow[b]{2}{*}{ Calves } & Triple Phosphate & Prismatic, coffin lid shaped, star and elongated rod shaped, feathery or fern like \\
\hline & $\begin{array}{c}\text { Calcium/Amorphous Phosphate, calcium } \\
\text { Carbonate , calcium oxalate, Uric acid Silica } \\
++ \text { to }++++\end{array}$ & $\begin{array}{l}\text { Spherical Granules amorphous, rosette shaped } \\
\text { A cluster of } 1 \text { to } 4 .\end{array}$ \\
\hline Sheep & $\begin{array}{l}\text { Calcium oxalate } \\
\text { Triple Phosphate } \\
\text { Uric acid }\end{array}$ & $\begin{array}{l}\text { Square envelop } \\
\text { coffin lid } \\
\text { Diamond shaped }\end{array}$ \\
\hline Goat & $\begin{array}{l}\text { Cystine } \\
\text { Struvite, }\end{array}$ & Hexagonal shaped \\
\hline
\end{tabular}

Table 3: Patterns of crystals in urine of Calves Sheep and Goats. 
Citation: Gazi MA, Makhdoomi DM, Mir SA, Sheikh GN (2016) Urinalysis - A Diagnostic Factor for Urolithiasis and Prognostic Factor for its Recurrence in Young Ruminants. J Veterinar Sci Technol 7: 336. doi:10.4172/2157-7579.1000336

Page 4 of 6

\begin{tabular}{|c|c|c|c|c|c|c|c|c|c|}
\hline \multirow[b]{2}{*}{ Period } & & \multicolumn{7}{|c|}{ Groups } & \multirow[b]{2}{*}{ Mean } \\
\hline & & $A_{1}(N=12)$ & $\begin{array}{c}B \\
(N=12)\end{array}$ & $\begin{array}{c}C \\
(N=9)\end{array}$ & $\begin{array}{c}D \\
(N=9)\end{array}$ & $\begin{array}{c}E \\
(N=8)\end{array}$ & $\begin{array}{c}F \\
(N=6)\end{array}$ & $\begin{array}{c}G \\
(N=6)\end{array}$ & \\
\hline \multirow{3}{*}{0 hour } & $\mathrm{Ca}$ & 4.91 & 5.43 & 7.02 & 4.58 & 4.91 & 4.85 & 4.84 & 5.17 \\
\hline & $P$ & 6.65 & 6.93 & 7.64 & 5.37 & 5.79 & 4.33 & 4.85 & 6.03 \\
\hline & $\mathrm{Mg}$ & 3.95 & 6.96 & 3.47 & 4.38 & 2.63 & 4.15 & 4.50 & 4.41 \\
\hline \multirow{3}{*}{3 hour } & $\mathrm{Ca}$ & 4.78 & 5.39 & 9.33 & 4.60 & 5.99 & 6.85 & 5.00 & 5.70 \\
\hline & $\mathrm{P}$ & 6.56 & 5.70 & 7.04 & 5.34 & 5.69 & 4.28 & 4.81 & 5.74 \\
\hline & $\mathrm{Mg}$ & 3.92 & 6.69 & 8.75 & 5.06 & 6.25 & 7.82 & 7.80 & 6.43 \\
\hline \multirow{3}{*}{24 hour } & $\mathrm{Ca}$ & 5.04 & 5.56 & 9.48 & 6.42 & 7.07 & 6.86 & 7.06 & 6.56 \\
\hline & $P$ & 6.17 & 6.48 & 7.21 & 5.06 & 5.38 & 4.25 & 4.39 & 5.67 \\
\hline & $\mathrm{Mg}$ & 4.15 & 6.84 & 8.61 & 5.04 & 6.20 & 7.51 & 7.70 & 6.40 \\
\hline \multirow{3}{*}{72 hour } & $\mathrm{Ca}$ & 6.28 & 6.67 & 10.25 & 6.94 & 6.99 & 7.56 & 6.48 & 7.10 \\
\hline & $\mathrm{P}$ & 6.13 & 6.45 & 6.49 & 4.75 & 5.11 & 4.05 & 3.63 & 5.34 \\
\hline & $\mathrm{Mg}$ & 3.92 & 6.53 & 8.60 & 4.18 & 5.99 & 7.33 & 7.41 & 6.03 \\
\hline \multirow{3}{*}{ Restoration } & $\mathrm{Ca}$ & 9.11 & 8.24 & 10.73 & 7.85 & 8.51 & 7.47 & 6.66 & 8.36 \\
\hline & $\mathrm{P}$ & 5.65 & 5.48 & 5.59 & 4.74 & 4.74 & 3.49 & 3.39 & 4.86 \\
\hline & $\mathrm{Mg}$ & 3.37 & 5.75 & 6.91 & 3.26 & 5.99 & 6.82 & 6.78 & 5.26 \\
\hline \multirow{3}{*}{ Mean } & $\mathrm{Ca}$ & 6.02 & 6.27 & 9.36 & 6.08 & 6.69 & 6.56 & 6.00 & \\
\hline & $P$ & 6.21 & 6.21 & 6.79 & 5.05 & 5.34 & 4.08 & 4.21 & \\
\hline & $\mathrm{Mg}$ & 3.86 & 6.56 & 7.27 & 4.38 & 5.41 & 6.73 & 6.84 & \\
\hline
\end{tabular}

Table 4: Mean Values of Urinary Calcium, phosphorous and magnesium ( $\mathrm{m}$ mol/litre) in urine before and after surgery at various intervals of obstructive Urolithiasis in different groups.

\begin{tabular}{|c|c|c|c|c|c|c|}
\hline Animals & 2 weeks & 4 weeks & 6 Weeks & 8 Weeks & Animals Screened at 8 weeks & $\%+v e$ \\
\hline Calves 84 & 2 & 2 & 1 & Nil & 69 (18) & $26.08 \%$ \\
\hline Sheep 17 & 1 & 1 & Nil & Nil & $15(5)$ & $33.33 \%$ \\
\hline Goat 12 & Nil & 2 & Nil & Nil & $9(2)$ & $22.22 \%$ \\
\hline
\end{tabular}

The values in Brackets indicate positive cases

Table 5: Recurrence of urolithiasis up to 2 months due to residual effect.

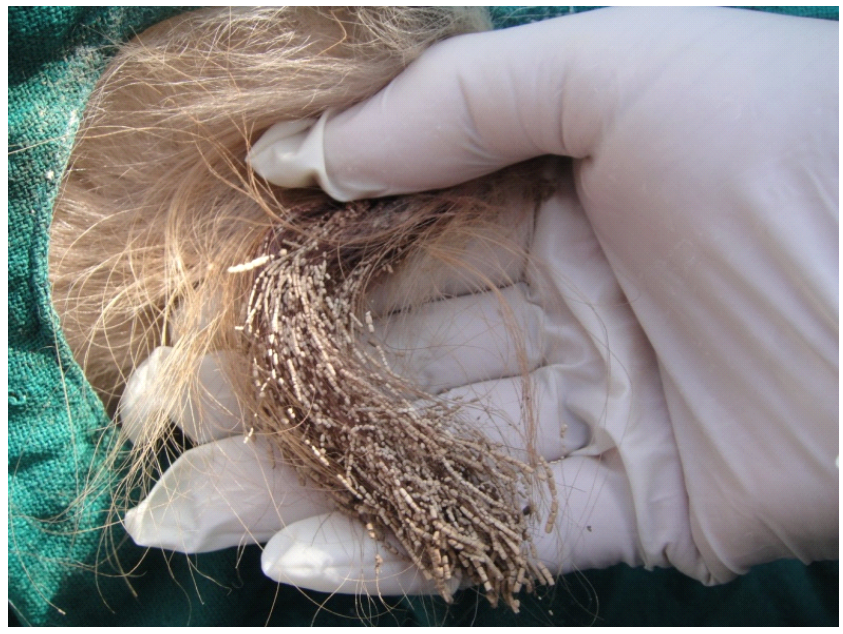

Figure 2: Calf screened a stone former manifesting clinical urolithiasis after 6 weeks the calculi are adhered to preputial hairs as garlands.

anticipated and managed [8]. It may also be indicated while postponing surgery [9]. Rakestraw et al. [10] reported a foul-smelling abdominal fluid and multiple adhesions between the loops of the small intestine and between the small intestine and bladder in a goat suffering from obstructive urolithiasis that had a history of repeated cystocentesis.

A total of 113 calves were subjected to screening as stone former and non-stone former by method as described by Teotia [4]. Out of 67 stone formers 21 (31.34\%) were presented for treatment to our Hospital with clinical manifestations of urolithiasis. In a study on clinical

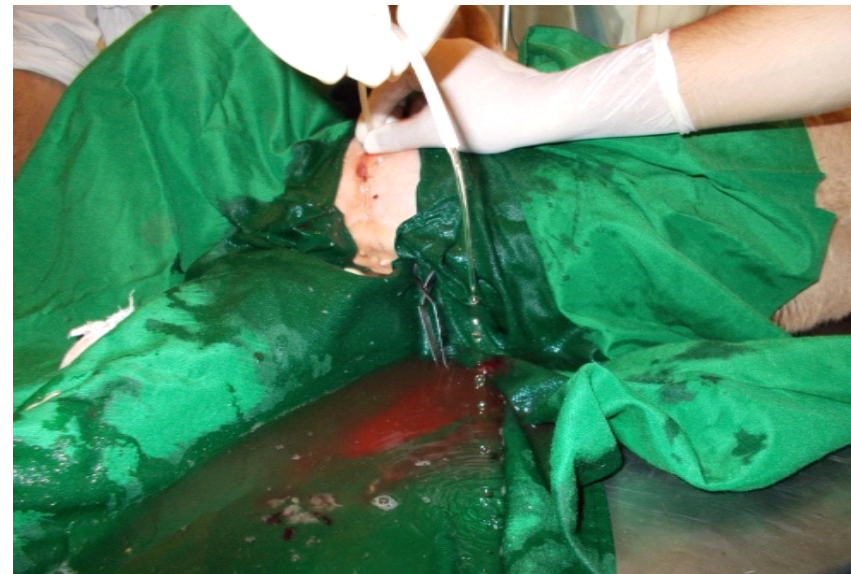

Figure 3: Catheterization in calf.

urolithiasis in calves Khan [11] recorded that screening can be a good index for prediction of urolithiasis cases up to the accuracy of 54 per cent. The percentage could be more. Teotia [4] demonstrated screening of animals as stone former and non-stone former and reported $60 \%$ accuracy. Hence it could be concluded that screening using a urine analyzer has an accuracy of $100 \%$, besides it is less invasive, instant, less time consuming and has no chances of error, hence should be a preferred method for the screening of animals for urolithiasis over Teotia [4] wherever the facility is available.

The crystal load and crystal score in all the groups was maximum on the day of presentation and subsequently declined after surgery due 


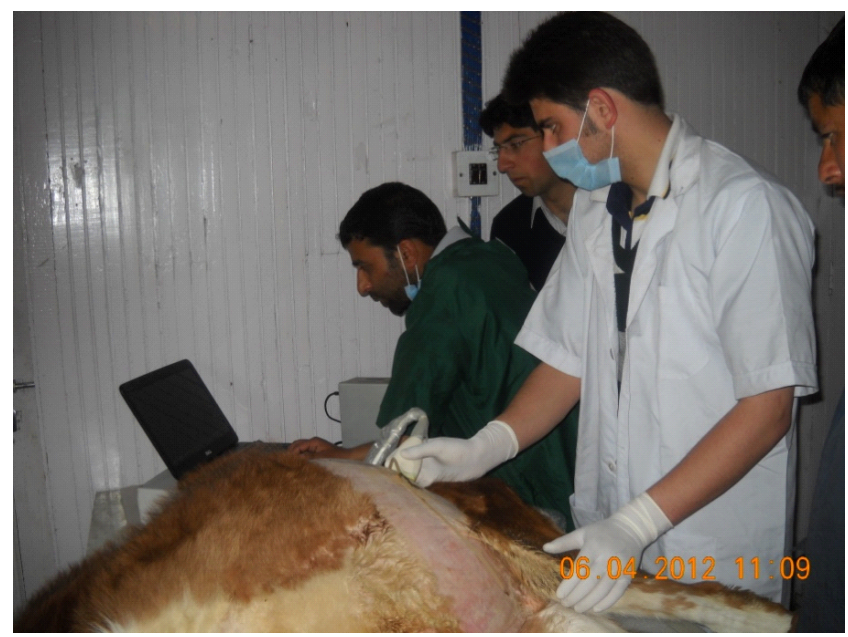

Figure 4: Ultrasonography in progress.

elimination of crystal via urine due to more formation of such crystals. The crystal score decreased significantly after surgery but the animals continued to show the crystal score positive due to the residual effect. The crystal number is of greater significance than crystal shape and size [12]. The types of the crystals vary in different species of animals and crystalluria was an indicator to evaluate the patient for uroliths. Crystals also form as a consequence of disease processes that alter urine composition.

Animals were presented for screening as stone and non-stone formers. In calves the positive percentage was 26.08, in Rams 33.33 and in Bucks the positive percentage was $22.22 \%$ (Figure 2), in study in Srinagar city Khan [11] reported an recurrence percentage of 54.285 in calves treated for urolithiasis at different intervals of disease

\section{Biochemical analysis of urine}

The improvement in the calcium range, decrease in phosphorous and magnesium levels towards normalcy could be due to regain of appetite, discontinuation of ruminant ration seems a reason in absence of detailed acid-base study. The inverse effect of the elevated calcium level in the blood has been reported by Singh et al. [13] and Khan [11]. Stewart et al. [14] and Crook and Robbins [15] reported high urinary excretion of phosphorus, and low urinary calcium excretion in lambs which readily developed phosphatic calculi. Crook and Robbins [15] demonstrated that lambs which developed urolithiasis had higher serum levels and lower urinary excretions of magnesium $(\mathrm{p}<0.05)$ then unaffected animals. Increased dietary magnesium has also been shown to increase the incidence of calculi in feedlot lambs even at a normal $\mathrm{Ca}$ to $\mathrm{P}$ ratio, but especially in the presence of high urinary phosphorus $[16,17]$.

Goats of various breeds and purposes have been documented with urolithic stone problems in captivity [18]. These stones often occur when a mainly concentrate diet is presented to the goats, with a high phosphorus content. Normal healthy ruminant species have very low urinary phosphorus excretion; due to phosphorus recycling mechanisms. Any excess phosphorus absorbed will be re-secreted into the digestive tract as saliva and lost in the faces. High grain, low roughage diet decreases the formation of saliva, resulting in excess phosphorus excretion into the urine [3].

From the present study it could be concluded that the urinalysis is a simple and reliable test to confirm urinary tract disease and identify path physiologic mechanisms associated with the underlying cause. Crystal formation indicates that urine is sufficiently saturated such that it could support the formation and growth of uroliths of that respective mineral type. If sufficient numbers of crystals are present, with a concomitant inflammatory process, male small ruminants are at risk for calculi formation. Alterations in Urinary Calcium Phosphorous and Magnesium cannot be fixed as a diagnostic or prognostic value for detection of uroliths forming animals to a fear degree of accuracy. The recurrence due to residual effect was $26.08 \%$ calves the positive percentage was, $33.33 \%$ in Rams and in $22.22 \%$ Bucks. Screening revealed 59.29\% non-stone former, $40.70 \%$ stone former from which $61.75 \%$ animals manifested urolithiasis within 2 months (Table 5). The Pre and post collections showed crystal load in urine in all the groups was maximum on presentation day and subsequently declined irrespective of the severity of the clinical manifestations however some cases showed crystals even after operation for some time. The crystals varied from triple Phosphate, calcium/amorphous phosphate, calcium Carbonate, calcium oxalate to uric acid in different species under study. In the present study on the day of admission varying degree of dehydration was present in all the animals, which could have raised the relative concentration of urinary mineral solutes and increased the likelihood of their precipitation.

\section{References}

1. Monoghan ML, Boy MG (1990) Diseases of the Renal System-Ruminant Renal System. In: Large Animal Internal Medicine. Smith BP (ed.). Mosby, USA, pp: 895-899.

2. Braun U, Schefer U, Föhn J (1992) Urinary tract ultrasonography in normal rams and in rams with obstructive urolithiasis. Can Vet J 33: 654-659.

3. Belknap EB, Pugh DG (2002) Diseases of the urinary system. In: Sheep and Goat Medicine. Pugh DG, Baird AN (Eds.). W. B. Saunders Company: Philadelphia.

4. Teotia G (1975) Screening of calves as normal and stone formers. Veterinary Record 128: 234-238.

5. Kaser M, Stekol JA (1979) A critical study of the Carr-Price reaction for the determination of $\beta$-carotene and vitamin $A$ in biological materials. Transl Res 28: 904-909.

6. Amardor E, Urban J (1977) Simplified serum phosphorus analyses by continuous flow UV- spectrophotometry. Clinical Chemistry 18: 601-604.

7. Radostitis OM, Blood DC, Gray GC, Hinchcliff KW (2000) Veterinary Medicine: A Textbook of the Diseases of Cattle, Sheep, Pigs, Goats, and Horses. Bailliere Tindall, London, pp: 1877

8. Makhdoomi DM, Gazi MA (2012) Obstructive Urolithiasis - A Review. Vet World 6: 233-238.

9. Van Metre D (2004) Urolithiasis. In: Farm Animal Surgery. Fubini SL, Ducharme NG (Eds.) WB Saunders, New York, pp: 534-547.

10. Rakestraw PC, Fubini SL, Gilbert RO, Ward JO (1995) Tube cystostomy for treatment of obstructive urolithiasis in small ruminants. Vet Surg 24: 498-505.

11. Khan AM (2010) Surgical management of Urolithiasis in calves with possible role of calcium, phosphorous and magnesium shift in blood, urine and calculi. Thesis submitted to Sheri Kashmir University of Agricultural Sciences and Technology Kashmir in partial fulfilment of MVSc degree.

12. Clark P, Swenson CL, Osborne CA, Ulrich LK (1999) Calcium oxalate crystalluria in a goat. J Am Vet Med Assoc 215: 77-78.

13. Singh J, Singh AP, Peshin PK, Singh M, Sharma SK (1983) Studies on the effects of total nephrectomy in sheep. Can J Comp Med 47: 217-221.

14. Stewart SR, Emerick RJ, Pritchard RH (1991) Effects of dietary ammonium chloride and variations in calcium to phosphorus ratio on silica urolithiasis in sheep. J Anim Sci 69: 2225-2229.

15. Crookshank HR, Robbins JD (1962) A reciprocal relationship between the 
Citation: Gazi MA, Makhdoomi DM, Mir SA, Sheikh GN (2016) Urinalysis - A Diagnostic Factor for Urolithiasis and Prognostic Factor for its Recurrence in Young Ruminants. J Veterinar Sci Technol 7: 336. doi:10.4172/2157-7579.1000336

Page 6 of 6

urinary excretion of magnesium and phosphorus in wether lambs. Nature 396: 1343.

16. Bezeau LM, Bailey CB, Slen SB (1961) Silica urolithiasis in beef cattle IV. The relationship between the $\mathrm{pH}$ and buffering capacity of ash of certain feeds, $\mathrm{pH}$ of urine and urolithiasis. Can J Anim Sci 41: 49-54.
17. Larson BL (1996) Identifying, treating and preventing bovine urolithiasis. Vet Med 91: 366-377.

18. Kimberling CV, Arnold KS (1983) Diseases of the urinary system of sheep and goats. Vet Clin North Am Large Anim Pract 5: 637-655. 